\title{
Small bowel adenocarcinoma in Crohn's disease: A case report and review of literature
}

\author{
Irmgard E Kronberger, Ivo W Graziadei, Wolfgang Vogel
}

Irmgard E Kronberger, Ivo W Graziadei, Wolfgang Vogel, Department of Gastroenterology and Hepatology, Medical University Innsbruck, Austria

Correspondence to: Irmgard E Kronberger, c/o Wolfgang Vogel, MD, Department of Gastroenterology and Hepatology, Anichstrasse 35, A-6020 Innsbruck, Austria. ie.kronberger@aon.at Telephone: +43-512-50423401 Fax: +43-512-50424052

Received: 2005-06-22

Accepted: 2005-07-28

\begin{abstract}
Small bowel adenocarcinomas are remarkable for their rarity, difficult diagnosis and poor prognosis. Here we report an unusual case of a 33-year-old patient in whom infiltrative adenocarcinoma of the small bowel was diagnosed after a 10-year history of Crohn's disease. In most previously reported cases, detection of Crohn's disease was subsequent to that of carcinoma of the small bowel or the patients involved had an even longer history of the disease. Our literature review suggests that the risk of small bowel adenocarcinoma is higher in patients with Crohn's disease than in the overall population. We present details on epidemiology as well as clinical and diagnostic aspects of this rare disease entity.
\end{abstract}

(C) 2006 The WJG Press. All rights reserved.

Key words: Crohn's disease; Small bowel adenocarcinoma; Case report

Kronberger IE, Graziadei IW, Vogel W. Small bowel adenocarcinoma in Crohn's disease: A case report and review of literature. World J Gastroenterol 2006; 12(8): 1317-1320

http://www.wjgnet.com/1007-9327/12/1317.asp

\section{INTRODUCTION}

The incidence of inflammatory bowel disease (IBD) is increasing since World War II with levels around 6/100000 for Crohn's disease (CD) and 15 to 20/100000 for ulcerative colitis, a marked rise in the age group between twenty to forty years for both entities ${ }^{[1]}$.

The ulcerations occur primarily in the small and large intestines, but may appear anywhere in the digestive tract from the mouth to the anus. Common symptoms of CD are abdominal pain, often in the lower right area, and diarrhoea, but rectal bleeding, weight loss and fever may also appear. Children with CD may suffer stunted growth and delayed development. The severity of the symptoms fluctuates erratically over time. Patients experience flareups between intervals of remission or reduced symptoms. The causes of this disease have not been identified yet; but both genetic factors that induce continued abnormal activation of the immune system ${ }^{[2,3]}$ and environmental triggers, like Mycobacterium avium subspecies paratuberculosis $^{[4]}$, are likely to be involved.

Oral or topical preparations of 5-aminosalicylates represent first line therapy, and steroids and azathioprine are used in severe cases; metronidazole and TNF-alpha antibodies are used in fistulating disease. Fifty to seventy percent of Crohn's patients undergo surgery for progression of disease indicated by the presence of fistulas, tumor in the abdomen and development of ileus.

IBD is linked to large and small bowel carcinoma, especially to adenocarcinomas ${ }^{[5-7]}$. In the last twenty years, colorectal cancer has become the fourth most common cancer worldwide, and in Europe colorectal cancer represents the second most frequent cause of death from any cancer in $\operatorname{men}^{[8]}$. Even though only about $1 \%$ of all colorectal cancers is associated with ulcerative colitis or Crohn's colitis, the risk of colorectal cancer for any ulcerative colitis patient is found to be $2 \%$ at $10,8 \%$ at 20 and $18 \%$ at 30 years, duration of disease, regardless of disease extent ${ }^{[9,10]}$.

Small bowel carcinomas are uncommon representing only $1 \%$ to $5 \%$ of all gastrointestinal tract malignancies. The first observations suggested that particularly surgically bypassed bowel segments were exposed to high risk of small bowel adenocarcinoma ${ }^{[11,12]}$. However, the risk of small bowel carcinoma in patients with CD is much higher, being up to 60 -fold of that in the general population ${ }^{[13,14]}$.

Neither clear risk factors nor methods for early diagnosis have been established by the few studies on this distinctly uncommon complication within this rare disease. Here we report on a patient in whom infiltrative adenocarcinoma of the ileum was diagnosed after a 10-year history of $\mathrm{CD}$ and also discuss possible risk factors, symptoms, feasible diagnostic approaches and treatment options on the basis of published reports.

\section{CASE REPORT}

A 33-year-old man presented in 1992 with recurrent pyrexia and abdominal pain but no diarrhoea. Enteroclysis 
was performed and a diagnosis of ileal CD was made. His family history was negative for this disease. For persistent abdominal pain under therapy with 5-aminosalicylates, he was put on corticosteroids (prednisone, $12.5 \mathrm{mg}$ daily). In the following four years the patient experienced repeated episodes of abdominal pain without diarrhoea.

Two years later, an abdominal ultrasound performed for reassessment of the disease, showed a thick intestinal loop from the left to the right upper abdomen. Unfortunately no further diagnostic or therapeutic steps were undertaken at that time.

In 2002, the patient, complaining of increasing abdominal pain, underwent ileocolonoscopy, which yielded no suspicious macroscopic or histopathological findings. Blood tests showed mild anaemia, signs of malabsorption (low proteins, phosphorous and iron deficiency) but none for inflammation. The recommended enteroclysis of the small bowel was not performed. In order to reduce corticosteroids, therapy with azathioprine was initiated $(2 \mathrm{mg} / \mathrm{kg}$ weight/ per day).

In June 2003 he presented again with abdominal pain, vomiting and distended abdomen. Enteroclysis showed a dilated intestinal loop of the ileum, a pseudotumor in the right abdomen and two stenotic areas, one of which was high-grade and located in the right upper abdomen (Figure 1). Prednisone was increased to $50 \mathrm{mg} /$ day, in addition to metronidazole and ciprofloxacine. Three weeks later, with a deterioration of obstructive symptoms, the patient underwent surgery.

The surgical specimens consisted of a $45 \mathrm{~cm}$ and a $7 \mathrm{~cm}$ long resected segments. Macroscopic examination showed high-grade inflammatory alteration of the ileum along a $20 \mathrm{~cm}$ segment and two upstream high-grade stenoses. The external surface of the diseased segment appeared brownish discoloured with adhering connective tissue. The internal surface of the ileum showed discontinuous mucous membrane, streaks of ulcers and whitened swelling of the bowel wall. Some foci had a 'cobblestone' appearance. The $7 \mathrm{~cm}$ long segment had a stenotic 'sandglass' formation.

Extensive histopathological examination in the first stricture revealed a poorly differentiated adenocarcinoma infiltrating the serosa, incipient infiltration of the mesenteric fat and lymphangiosis carcinomatosa as well as a metastatic peritoneal range. Tumor had seeded seven out of eleven lymph nodes examined. The resected specimen also showed adenoma's dysplasia adjacent to the carcinoma. Extended antral metaplastic lesions within agglutinated villi up to one margin were found.

The second specimen revealed proper margins of resection. In the centre of the macroscopic stricture was another focus of the adenocarcinoma. In addition, moderately florid inflammatory infiltrates with acute erosions were detected, compatible with Crohn's disease.

Immunohistochemistry was negative for NSE and chromogranin, only a few tumor cells were slightly positive for synaptophysin. CEA level determined only after surgery was $54.2 \mathrm{ng} / \mathrm{ml}$ (normal $<50 \mathrm{ng} / \mathrm{ml}$ ).

The patient recovered well from surgery and then underwent chemotherapy according to Folfox IV-scheme with oxaliplatin, 5-fluorouracil and leucovorin in six cycles.

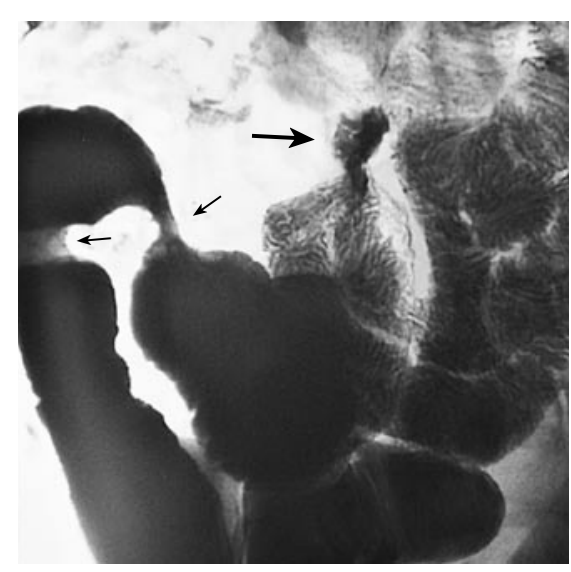

Figure 1 Enteroclysis: dilated intestinal loop of the ileum; altered Crohn's area (big arrow), one high grade and one low grade tumor stenosis in the right upper abdomen (two small arrows).

The patient tolerated the therapy quite well.

The computed tomography (CAT-scan) in October 2004 revealed up to two centimetres enlarged mesenteric and up to one centimetre enlarged retroperitoneal lymph nodes, without any further evidence for metastases. In November 2004 the patient presented with headache, vertigo and ambiopia and was diagnosed with meningeosis carcinomatosa. Intrathecal chemotherapy with methotrexate was started. He is now undergoing intrathecal chemotherapy with sustained-released cytarabine.

\section{DISCUSSION}

According to Parkin et al the age-standardized incidence of small intestine cancer (ICD-10 C17) ranges from 0.2 to 2.4 for males and from 0.2 to 1.8 for females worldwide $^{[15]}$. The 'Statistik Austria' National Registry has 1384 documented cases of small intestine cancer between $1983-2000^{[16]}$.

The association of $\mathrm{CD}$ with small bowel carcinoma is uncommon and to date only about 130 cases of small bowel carcinomas in patients with $\mathrm{CD}$ have been reported in the literature since the first description of this disease entity in $1956^{[17]}$. Cases and studies published in the last few decades, however, bear out from a 12-fold to an over 60 -fold increased risk of small bowel cancer in $\mathrm{CD}^{[13,14,18]}$. This is in contrast to publications that still emphasize the popular position that $\mathrm{CD}$ is primarily associated with carcinoma of the colon. Adenocarcinoma is the most common forms of all small bowel malignancy and there appears to be an increased risk for developing ileal carcinoma in $\mathrm{CD}$ patients $^{[19-23]}$.

Most of ileal carcinoma in CD are located in strictures $^{[11,24,25]}$ and are often incidentally diagnosed postoperatively as in our case report. The occult carcinomas in strictures pose a challenge to diagnostic investigations using conventional modalities such as small bowel series and upper and lower gastrointestinal endoscopy. CT is now considered the imaging modality of choice ${ }^{[26-28]}$, and a fat density target sign in $\mathrm{CT}^{[2]}$ is also getting greater attention as reliable marker for diagnosing $\mathrm{CD}$ or even small bowel carcinoma. Abdominal MRI ${ }^{[30]}$, double-contrast enteroclysis $^{[31]}$ and endoscopy ${ }^{[32]}$, especially video wireless capsule endoscopy ${ }^{[33,34]}$, are promising new diagnostic tools.

Other interesting characteristics are adjacent metapla- 
sia, adenoma and epithelial dysplasia ${ }^{[35-38]}$, which underline the importance of further research with respect to sequence-dysplasia in ileal adenocarcinomas in relation to Crohn's disease.

Risk factors for small intestine carcinoma in CD are chronic active course with stricture, fistulas and onset of disease before the age of 30 years ${ }^{[25,39,40]}$. Further reported risk factors are: early onset, age between 30 and 50 years, male sex and smoking ${ }^{[13,14,41-45]}$. Therapy of CD with corticosteroids, azathioprine and TNF-alpha antibodies are also considered as potential risk factors. It has been suggested in previous studies that azathioprine, administered mostly combined with steroids to patients with a long history of Crohn's disease, frequent recurrence or those allergic to 5 -aminosalicylates has a carcinogenic potential ${ }^{[14,46-49]}$. In the light of these reports, it is interesting to raise the question whether azathioprine therapy initiated in our patient after normal ileocolonoscopy 18 mo before diagnosis of carcinoma might have contributed to the acceleration of the malignant disease. In contrast to azathioprine, 5-aminosalicylates are considered preventive against the development of large and small bowel adenocarcinoma in inflammatory bowel disease ${ }^{[13,23,50-53]}$. Mesalazine is now used for treating light to moderate Crohn's colitis and ileitis postoperatively to maintain remissions, but its potential to prevent malignancy needs to be evaluated. TNF-alpha antibodies, also mostly combined with immunosuppression, are used in patients with refractory, steroid-dependent and fistulating CD. There is a theoretical risk of increased rate of malignancies due to antagonism of TNF-alpha, but to date there is no clear proof of such an effect ${ }^{[54-56]}$.

Prognosis of small bowel adenocarcinoma is poor, and the mortality at 1 and 2 years ranges from $30-60 \%$ dependent on the stage of the cancer ${ }^{[13,21,57-59]}$.

Further prognostic factors are based on histologic findings such as positive surgical margins, poor differentiation, depth of tumor invasion, positive lymph nodes and extramural venous spread in small bowel adenocarcinoma ${ }^{[60]}$.

\section{CONCLUSION}

Small bowel adenocarcinoma in Crohn's disease is rare and preoperative diagnosis continues to present challenges. Long-term prognosis is poor - all the more it is important to be vigilant. Patients with increased risk are those with longstanding complicated CD presenting with a 'de novo' clinical picture of obstruction. Male patients, in particular smokers, are considered to be at increased risk. Since the diagnosis is difficult to make, attending physicians must exercise a high level of clinical suspicion for operative cure. The preventive potential of 5-ASA in adenocarcinoma of the colon suggests that this drug should be preferred to azathioprine in patients to maintain remission.

\section{REFERENCES}

1 Ekbom A. The epidemiology of IBD: a lot of data but little knowledge. How shall we proceed? Inflamm Bowel Dis 2004; 10 Suppl 1: S32-S34

2 Oostenbrug LE, van Dullemen HM, te Meerman GJ, Jansen PL. IBD and genetics: new developments. Scand J Gastroenterol Suppl 2003; : 63-68
3 Esters N, Pierik M, van Steen K, Vermeire S, Claessens G, Joossens S, Vlietinck R, Rutgeerts P. Transmission of CARD15 (NOD2) variants within families of patients with inflammatory bowel disease. Am J Gastroenterol 2004; 99: 299-305

4 Greenstein RJ. Is Crohn's disease caused by a mycobacterium? Comparisons with leprosy, tuberculosis, and Johne's disease. Lancet Infect Dis 2003; 3: 507-514

5 Torres C, Antonioli D, Odze RD. Polypoid dysplasia and adenomas in inflammatory bowel disease: a clinical, pathologic, and follow-up study of 89 polyps from 59 patients. Am J Surg Pathol 1998; 22: 275-284

6 Munkholm P. Review article: the incidence and prevalence of colorectal cancer in inflammatory bowel disease. Aliment Pharmacol Ther 2003; 18 Suppl 2: 1-5

7 Langholz E, Munkholm P, Davidsen M, Binder V. Colorectal cancer risk and mortality in patients with ulcerative colitis. Gastroenterology 1992; 103: 1444-1451

8 Boyle P, Langman JS. ABC of colorectal cancer: Epidemiology. BMJ 2000; 321: 805-808

9 Eaden JA, Abrams KR, Mayberry JF. The risk of colorectal cancer in ulcerative colitis: a meta-analysis. Gut 2001; 48: 526-535

10 Judge TA, Lewis JD, Lichtenstein GR. Colonic dysplasia and cancer in inflammatory bowel disease. Gastrointest Endosc Clin N Am 2002; 12: 495-523

11 Barwood N, Platell C. Case report: adenocarcinoma arising in a Crohn's stricture of the jejunum. J Gastroenterol Hepatol 1999; 14: $1132-1134$

12 Mohan IV, Kurian KM, Howd A. Crohn's disease presenting as adenocarcinoma of the small bowel. Eur J Gastroenterol Hepatol 1998; 10: 431-432

13 Solem CA, Harmsen WS, Zinsmeister AR, Loftus EV Jr. Small intestinal adenocarcinoma in Crohn's disease: a case-control study. Inflamm Bowel Dis 2004; 10: 32-35

14 Jess T, Winther KV, Munkholm P, Langholz E, Binder V. Intestinal and extra-intestinal cancer in Crohn's disease: followup of a population-based cohort in Copenhagen County, Denmark. Aliment Pharmacol Ther 2004; 19: 287-293

15 Parkin D.M. WSL, Forlay J., Teppo L., Thomas D.B., ed. Agestandardized (world) incidence (per 100,000) and cumulative (0-74) incidence (percent) rates and standard errors. Incidence in Five Continents Vol. VIII, ed. I.S. Publications. Vol. 155. 2002, IARC Scientific Publications: Lyon. 549-551

16 AustrianStatistics, Indicence and Mortality of small intestine cancer, Mortality of Crohn's disease 1983 - 2000. 2004, Statistik Austria: Vienna.

17 Koga H, Aoyagi K, Hizawa K, Iida M, Jo Y, Yao T, Oohata Y, Mibu R, Fujishima M. Rapidly and infiltratively growing Crohn's carcinoma of the small bowel: serial radiologic findings and a review of the literature. Clin Imaging 1999; 23: 298-301

18 Lewis JD, Deren JJ, Lichtenstein GR. Cancer risk in patients with inflammatory bowel disease. Gastroenterol Clin North Am 1999; 28: 459-477

19 Nesbit RR Jr, Elbadawi NA, Morton JH, Cooper RA Jr. Carcinoma of the small bowel. A complication of regional enteritis. Cancer 1976; 37: 2948-2959

20 Beachley MC, Lebel A, Lankau CA Jr, Rothman D, Baldi A. Carcinoma of the small intestine in chronic regional enteritis. Am J Dig Dis 1973; 18: 1095-1098

21 Michelassi F, Testa G, Pomidor WJ, Lashner BA, Block GE. Adenocarcinoma complicating Crohn's disease. Dis Colon Rectum 1993; 36: 654-661

22 Frank JD, Shorey BA. Adenocarcinoma of the small bowel as a complication of Crohn's disease. Gut 1973; 14: 120-124

23 Bernstein CN, Blanchard JF, Kliewer E, Wajda A. Cancer risk in patients with inflammatory bowel disease: a populationbased study. Cancer 2001; 91: 854-862

24 Marchetti F, Fazio VW, Ozuner G. Adenocarcinoma arising from a strictureplasty site in Crohn's disease. Report of a case. Dis Colon Rectum 1996; 39: 1315-1321

25 Partridge SK, Hodin RA. Small bowel adenocarcinoma at a strictureplasty site in a patient with Crohn's disease: report of a case. Dis Colon Rectum 2004; 47: 778-781 
26 Furukawa A, Saotome T, Yamasaki M, Maeda K, Nitta N, Takahashi M, Tsujikawa T, Fujiyama Y, Murata K, Sakamoto T. Cross-sectional imaging in Crohn disease. Radiographics 2004; 24: 689-702

27 Horton KM, Fishman EK. Multidetector-row computed tomography and 3-dimensional computed tomography imaging of small bowel neoplasms: current concept in diagnosis. J Comput Assist Tomogr 2004; 28: 106-116

28 Buckley JA, Siegelman SS, Jones B, Fishman EK. The accuracy of CT staging of small bowel adenocarcinoma: $\mathrm{CT} /$ pathologic correlation. J Comput Assist Tomogr 1997; 21: 986-991

29 Chen S, Harisinghani MG, Wittenberg J. Small bowel CT fat density target sign in chronic radiation enteritis. Australas Radiol 2003; 47: 450-452

30 Schreyer AG, Geissler A, Albrich H, Scholmerich J, Feuerbach S, Rogler G, Volk M, Herfarth H. Abdominal MRI after enteroclysis or with oral contrast in patients with suspected or proven Crohn's disease. Clin Gastroenterol Hepatol 2004; 2: 491-497

31 Zhan J, Xia ZS, Zhong YQ, Zhang SN, Wang LY, Shu H, Zhu $\mathrm{ZH}$. Clinical analysis of primary small intestinal disease: A report of 309 cases. World J Gastroenterol 2004; 10: 2585-2587

32 Mpofu C, Watson AJ, Rhodes JM. Strategies for detecting colon cancer and/or dysplasia in patients with inflammatory bowel disease. Cochrane Database Syst Rev 2004; : CD000279

33 Voderholzer WA, Ortner M, Rogalla P, Beinholzl J, Lochs H. Diagnostic yield of wireless capsule enteroscopy in comparison with computed tomography enteroclysis. Endoscopy 2003; 35: 1009-1014

34 Jungles SL. Video wireless capsule endoscopy: a diagnostic tool for early Crohn's disease. Gastroenterol Nurs 2004; 27: 170-175

35 Sigel JE, Petras RE, Lashner BA, Fazio VW, Goldblum JR. Intestinal adenocarcinoma in Crohn's disease: a report of 30 cases with a focus on coexisting dysplasia. Am J Surg Pathol 1999; 23: 651-655

36 Rashid A, Hamilton SR. Genetic alterations in sporadic and Crohn's-associated adenocarcinomas of the small intestine. Gastroenterology 1997; 113: 127-135

37 Petras RE, Mir-Madjlessi SH, Farmer RG. Crohn's disease and intestinal carcinoma. A report of 11 cases with emphasis on associated epithelial dysplasia. Gastroenterology 1987; 93: 1307-1314

38 Jankowski JA, Bedford FK, Boulton RA, Cruickshank N, Hall C, Elder J, Allan R, Forbes A, Kim YS, Wright NA, Sanders DS. Alterations in classical cadherins associated with progression in ulcerative and Crohn's colitis. Lab Invest 1998; 78: 1155-1167

39 Lashner BA. Risk factors for small bowel cancer in Crohn's disease. Dig Dis Sci 1992; 37: 1179-1184

40 Christodoulou D, Skopelitou AS, Katsanos KH, Katsios C, Agnantis N, Price A, Kappas A, Tsianos EV. Small bowel adenocarcinoma presenting as a first manifestation of Crohn' s disease: report of a case, and a literature review. Eur J Gastroenterol Hepatol 2002; 14: 805-810

41 Kaerlev L, Teglbjaerg PS, Sabroe S, Kolstad HA, Ahrens W, Eriksson M, Guenel P, Hardell L, Launoy G, Merler E, Merletti F, Stang A. Medical risk factors for small-bowel adenocarcinoma with focus on Crohn disease: a European population-based case-control study. Scand J Gastroenterol 2001; 36: 641-646

42 Lightdale CJ, Sternberg SS, Posner G, Sherlock P. Carcinoma complicating Crohn's disease. Report of seven cases and review of the literature. Am J Med 1975; 59: 262-268

43 Church JM, Weakley FL, Fazio VW, Sebek BA, Achkar E, Carwell $\mathrm{M}$. The relationship between fistulas in Crohn's disease and associated carcinoma. Report of four cases and review of the literature. Dis Colon Rectum 1985; 28: 361-366

44 Munkholm P, Langholz E, Davidsen M, Binder V. Intestinal cancer risk and mortality in patients with Crohn's disease. Gastroenterology 1993; 105: 1716-1723

45 Sandmeier D, Bouzourene H. Adenocarcinoma in Crohn's disease. Histopathology 2003; 42: 404-405

46 Westaby S, Everett WG, Dick AP. Adenocarcinoma of the small bowel complicating Crohn's disease in a patient treated with azathioprine. Clin Oncol 1977; 3: 377-381

47 Fraser AG, Orchard TR, Robinson EM, Jewell DP. Long-term risk of malignancy after treatment of inflammatory bowel disease with azathioprine. Aliment Pharmacol Ther 2002; 16: 1225-1232

48 Connell WR, Kamm MA, Dickson M, Balkwill AM, Ritchie JK, Lennard-Jones JE. Long-term neoplasia risk after azathioprine treatment in inflammatory bowel disease. Lancet 1994; 343: 1249-1252

49 van Hogezand RA, Eichhorn RF, Choudry A, Veenendaal RA, Lamers CB. Malignancies in inflammatory bowel disease: fact or fiction? Scand J Gastroenterol Suppl 2002; 48-53

50 Lim WC, Hanauer SB. Controversies with aminosalicylates in inflammatory bowel disease. Rev Gastroenterol Disord 2004; 4: 104-117

51 Allgayer $\mathbf{H}$. Review article: mechanisms of action of mesalazine in preventing colorectal carcinoma in inflammatory bowel disease. Aliment Pharmacol Ther 2003; 18 Suppl 2: 10-14

52 Moody GA, Jayanthi V, Probert CS, Mac Kay H, Mayberry JF. Long-term therapy with sulphasalazine protects against colorectal cancer in ulcerative colitis: a retrospective study of colorectal cancer risk and compliance with treatment in Leicestershire. Eur J Gastroenterol Hepatol 1996; 8: 1179-1183

53 Ryan BM, Russel MG, Langholz E, Stockbrugger RW. Aminosalicylates and colorectal cancer in IBD: a not-so bitter pill to swallow. Am J Gastroenterol 2003; 98: 1682-1687

54 Tilg H, Knoflach P, Petritsch W, Vogelsang H, Reinisch W. Infliximab in the treatment of Crohn's disease -- a practical approach. Infliximab and chronic Crohn's disease--Consensus statement of the Working Group on Chronic Inflammatory Crohn's Diseases of the OGGH. Z Gastroenterol 2004; 42: 1256-1263

55 Wenzl HH, Reinisch W, Jahnel J, Stockenhuber F, Tilg H, Kirchgatterer A, Petritsch W. Austrian infliximab experience in Crohn's disease: a nationwide cooperative study with longterm follow-up. Eur J Gastroenterol Hepatol 2004; 16: 767-773

56 Dotan I, Yeshurun D, Hallak A, Horowitz N, Tiomny E, Reif S, Halpern Z, Rachmilewitz D. Treatment of Crohn's disease with anti TNF alpha antibodies--the experience in the Tel Aviv Medical Center. Harefuah 2001; 140: 289-293, 368

57 Dabaja BS, Suki D, Pro B, Bonnen M, Ajani J. Adenocarcinoma of the small bowel: presentation, prognostic factors, and outcome of 217 patients. Cancer 2004; 101: 518-526

58 Ribeiro MB, Greenstein AJ, Heimann TM, Yamazaki Y, Aufses AH Jr. Adenocarcinoma of the small intestine in Crohn's disease. Surg Gynecol Obstet 1991; 173: 343-349

59 Hawker PC, Gyde SN, Thompson H, Allan RN. Adenocarcinoma of the small intestine complicating Crohn's disease. Gut 1982; 23: 188-193

60 Abrahams NA, Halverson A, Fazio VW, Rybicki LA, Goldblum JR. Adenocarcinoma of the small bowel: a study of 37 cases with emphasis on histologic prognostic factors. Dis Colon Rectum 2002; 45: 1496-1502

S- Editor Guo SY L- Editor Zhang JZ E- Editor Cao L 